\title{
Identification of lysine acetylome in cervical cancer by label-free quantitative proteomics
}

\author{
Lu Zhang ${ }^{1+}$, Wanyue Wang ${ }^{2 \dagger}$, Shanqiang Zhang ${ }^{3+}$, Yuxin Wang ${ }^{1}$, Weikang Guo ${ }^{1}$, Yunduo Liu' ${ }^{1}$, Yaoxian Wang ${ }^{1 *}$ (D) \\ and Yunyan Zhang ${ }^{1 *}$
}

\begin{abstract}
Background: Lysine acetylation is a post-translational modification that regulates a diversity of biological processes, including cancer development.

Methods: Here, we performed the quantitative acetylproteomic analysis of three primary cervical cancer tissues and corresponding adjacent normal tissues by using the label-free proteomics approach.

Results: We identified a total of 928 lysine acetylation sites from 1547 proteins, in which 495 lysine acetylation sites corresponding to 296 proteins were quantified. Further, 41 differentially expressed lysine acetylation sites corresponding to 30 proteins were obtained in cervical cancer tissues compared with adjacent normal tissues (Fold change $>2$ and $\mathrm{P}<0.05$ ), of which 1 was downregulated, 40 were upregulated. Moreover, 75 lysine acetylation sites corresponding to 58 proteins were specifically detected in cancer tissues or normal adjacent tissues. Motif-X analysis showed that kxxxkxxxk, GkL, AxxEk, kLxE, and kkxxxk are the most enriched motifs with over four-fold increases when compared with the background matches. KEGG analysis showed that proteins identified from differently and specifically expressed peptides may influence key pathways, such as Notch signaling pathway, viral carcinogenesis, RNA transport, and Jak-STAT, which play an important role in tumor progression. Furthermore, the acetylated levels of CREBBP and S100A9 in cervical cancer tissues were confirmed by immunoprecipitation (IP) and Western blot analysis.
\end{abstract}

Conclusions: Taken together, our data provide novel insights into the role of protein lysine acetylation in cervical carcinogenesis.

Keywords: Cervical cancer, Acetylome, Label-free, Post-translational modification

\section{Background}

Cervical cancer is the fourth most common cancer and the second most frequent cause of cancer-related death among women, with an estimated 527,000 new cases and 265,700 deaths worldwide in 2012 [1,2]. More than $90 \%$ of cases are caused by human papillomavirus (HPV) infection [3]. Despite recent significant advances in

\footnotetext{
*Correspondence: wyxxs012@126.com; zhangyunyan_1972@163.com

†Lu Zhang, Wanyue Wang and Shanqiang Zhang contributed equally to this study

1 Department of Gynecology, Harbin Medical University Cancer Hospital, No. 150 Haping Road, Nangang District, Harbin 150081, Heilongjiang Province, China

Full list of author information is available at the end of the article
}

multimodality management of cervical cancer patients, most patients with advanced cervical cancer present with or develop metastatic disease, and the outcome in these patients is still disappointing [4-6]. To date, the molecular mechanisms underlying cervical carcinogenesis remain poorly understood. Therefore, there is an urgent need to identify the key mediators in cervical carcinogenesis and develop novel therapeutic strategies, thereby reducing mortality caused by this malignancy.

Post-translational modifications, occurring in almost all proteins, regulate a diversity of biological processes by altering the structural, conformational and physicochemical properties of proteins [7]. Among all the amino acid residues, the acetylation of lysine residue is one of the

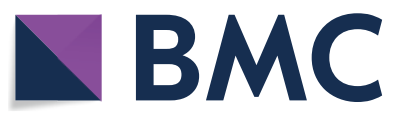

(c) The Author(s) 2020. This article is licensed under a Creative Commons Attribution 4.0 International License, which permits use, sharing, adaptation, distribution and reproduction in any medium or format, as long as you give appropriate credit to the original author(s) and the source, provide a link to the Creative Commons licence, and indicate if changes were made. The images or other third party material in this article are included in the article's Creative Commons licence, unless indicated otherwise in a credit line to the material. If material is not included in the article's Creative Commons licence and your intended use is not permitted by statutory regulation or exceeds the permitted use, you will need to obtain permission directly from the copyright holder. To view a copy of this licence, visit http://creativeco mmons.org/licenses/by/4.0/. The Creative Commons Public Domain Dedication waiver (http://creativecommons.org/publicdomain/ zero/1.0/) applies to the data made available in this article, unless otherwise stated in a credit line to the data. 
most commonly observed protein modification. Lysine acetylation is the transfer of an acetyl moiety from acetylCoA to its amino groups [8]. In early studies, lysine acetylation sites are frequently located in the nucleus, such as histones and other transcription factors [9]. However, recent evidence indicates that lysine acetylation is widespread in almost every compartment of a cell, such as the cytoplasm and mitochondria, and regulates multiple metabolic processes, including citric acid cycle, glycolysis, and fatty acid metabolism [10-12]. Furthermore, aberrant lysine acetylation has been implicated in tumorigenesis and may be a promising novel therapeutic target for cancer [13, 14]. In particular, aberrant lysine acetylation is also associated with cervical cancer development [15]. To the best of our knowledge, however, there are no reports on large scale analyses of aberrant lysine acetylation in cervical cancer development.

In order to explore the novel lysine acetylation proteins involved in the development of cervical cancer, the present study investigated the differential lysine acetylome profile between primary cervical cancer tissues and corresponding adjacent normal tissues by using a rigorous label-free quantitative mass spectrometry approach. Furthermore, several acetylated proteins were confirmed by immunoprecipitation (IP) and Western blot analysis.

\section{Materials and methods Patients and specimens}

Primary cancer tissues and corresponding adjacent normal tissues were obtained from three HPV infected patients with cervical squamous cell carcinoma who underwent surgical resection at our hospital. All the cervical cancer patients were diagnosed as stage IB, with a mean age of 61.3 years (range, 59-64 years). None of the patients received radiotherapy, chemotherapy, or other medical treatments before surgery. Surgically removed tissue samples were immediately immersed in liquid nitrogen until protein extraction. Written informed consent was obtained from each patient prior to surgery, and this study was approved by the Ethics Review Board of our institute and adhered to the principles of the Declaration of Helsinki and Title 45, U.S. Code of Federal Regulations, Part 46, Protection of Human Subjects, effective December 13, 2001.

\section{Protein extraction}

The tissue samples were homogenized in guanidine lysis buffer and then subjected to ultrasound treatment. After boiled at $100{ }^{\circ} \mathrm{C}$ for $15 \mathrm{~min}$, the lysis was centrifuged at $14,000 \mathrm{~g}$ for $40 \mathrm{~min}$. The supernatant was collected, and the protein concentrations were quantified by the bicinchoninic acid assay (BCA).

\section{Protein digestion and acetyl peptide enrichment}

The protein extract containing $10 \mathrm{mg}$ of proteins from each sample was added with Dithiothreitol (DTT) was added to each protein extract (containing $10 \mathrm{mg}$ proteins) to a final concentration of $10 \mathrm{mM}$. After incubation at $37^{\circ} \mathrm{C}$ for $2.5 \mathrm{~h}$, the mixture was alkylated with $50 \mathrm{mM}$ iodoacetamide (IAA) for $30 \mathrm{~min}$ at room temperature in dark and diluted by adding $\mathrm{ddH}_{2} \mathrm{O}$ to urea concentration to about 1.5 M. Subsequently, the proteins were digested with trypsin at 1:50 trypsin at $37^{\circ} \mathrm{C}$ for $18 \mathrm{~h}$. After desalination and lyophilization, the samples were reconstituted with $1.4 \mathrm{~mL}$ immunoaffinity purification (IAP) buffer and incubated with anti-Ac-lysine antibody beads (PTMScan, Cell Signaling Technology, Beverly, MA, USA) at $4{ }^{\circ} \mathrm{C}$ for $1.5 \mathrm{~h}$ to enrich Kac peptides. Then, the beads were washed three times with IAP buffer, and the enriched peptides were eluted with $0.15 \%$ trifluoroacetic acid (TFA). Finally, the peptides were desalted with C18 STAGE Tips (Millipore, Billerica, MA, USA).

\section{Liquid chromatography tandem mass spectrometry (LC- MS/MS) analysis}

LC-MS analysis was achieved on an EASY-nLC1000 System equipped with an SC200 EASY-Column $10 \mathrm{~cm} \times 150 \mu \mathrm{m}$ column at a flow rate of $300 \mathrm{~nL} / \mathrm{min}$. The mobile phase A was $0.1 \%$ formic acid in acetonitrile ( $2 \%$ acetonitrile) and mobile phase B was $0.1 \%$ formic acid in acetonitrile ( $84 \%$ acetonitrile). The peptides were separated by the following gradient elution: $0-110 \mathrm{~min}$ : gradient increase from 0 to $55 \%$ for B; $110-118$ min: gradient increase from $55 \%$ to $100 \%$ for $\mathrm{B} ; 118-120 \mathrm{~min}$ : hold $100 \%$ for B. The eluted peptides were analyzed with a Q-Exactive mass spectrometer. The MS and MS/ MS information were collected in the positive ion mode and acquired across the mass range of 350-1800 m/z followed by the top $20 \mathrm{MS} / \mathrm{MS}$ scans.

\section{Bioinformatic analysis}

The raw MS data were analyzed using the MaxQuant software, and the $P$ value of each protein was analyzed by Student's t-test using the Perseus program. The acetylated peptides with a fold-change $<0.5$ or $>2$ and $\mathrm{P}<0.05$ were considered differentially expressed. The Blast2Go program was used for the functional annotations of the identified proteins and the Kyoto Encyclopaedia of Genes and Genomes (KEGG) pathway enrichment analysis.

\section{Co-immunoprecipitation (Co-IP) and immunoblotting}

The proteins were extracted from cervical tissues by using RIPA lysis buffer (Beyotime Biotechnology, Shanghai, China). The supernatant was incubated with antiMYH11 (Abcam, Cambridge, MA, USA), anti-CREBBP 

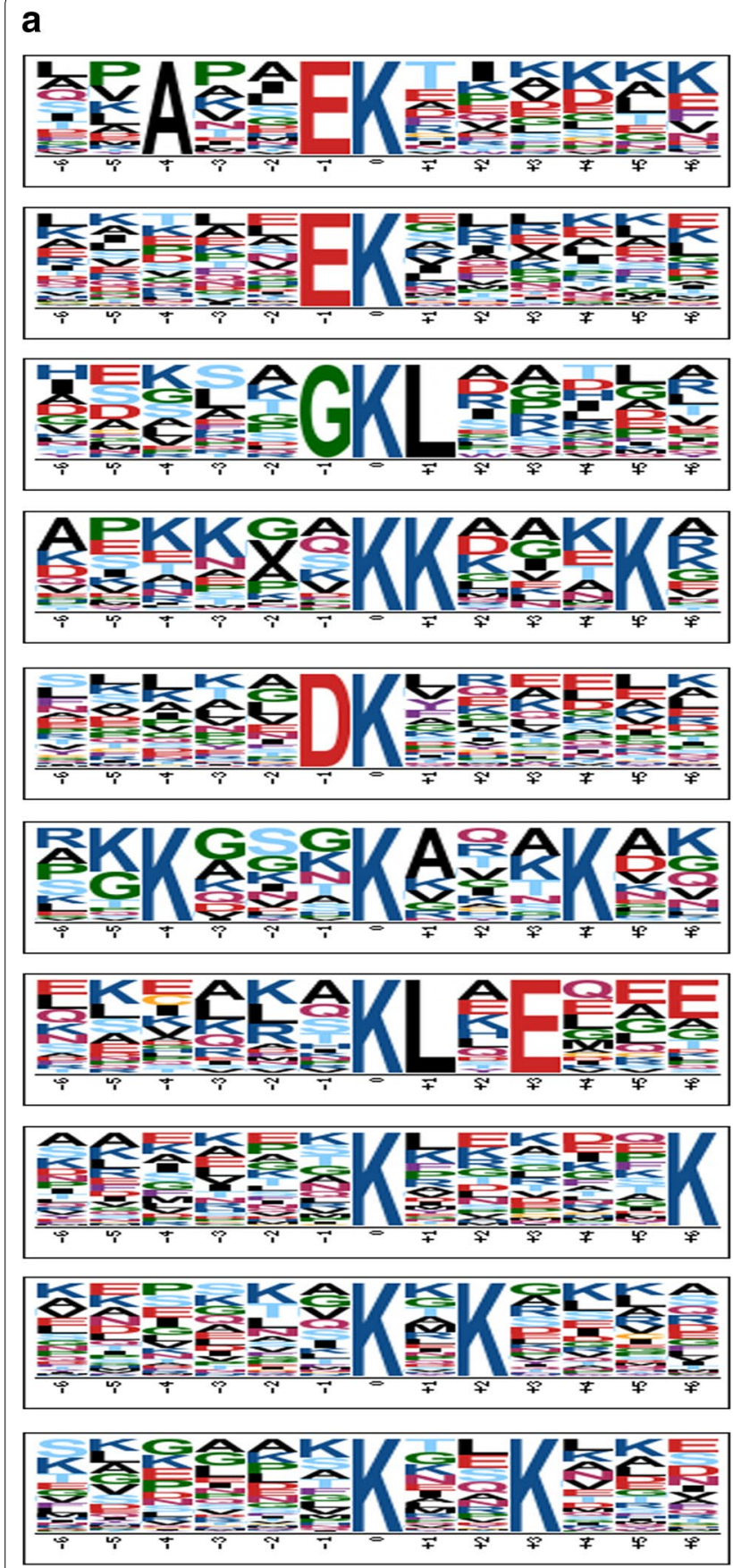

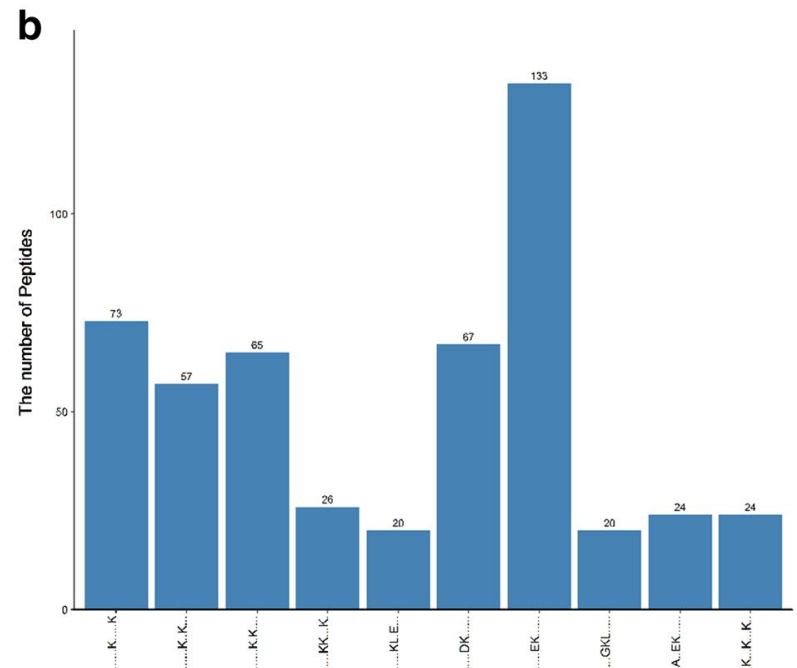

C

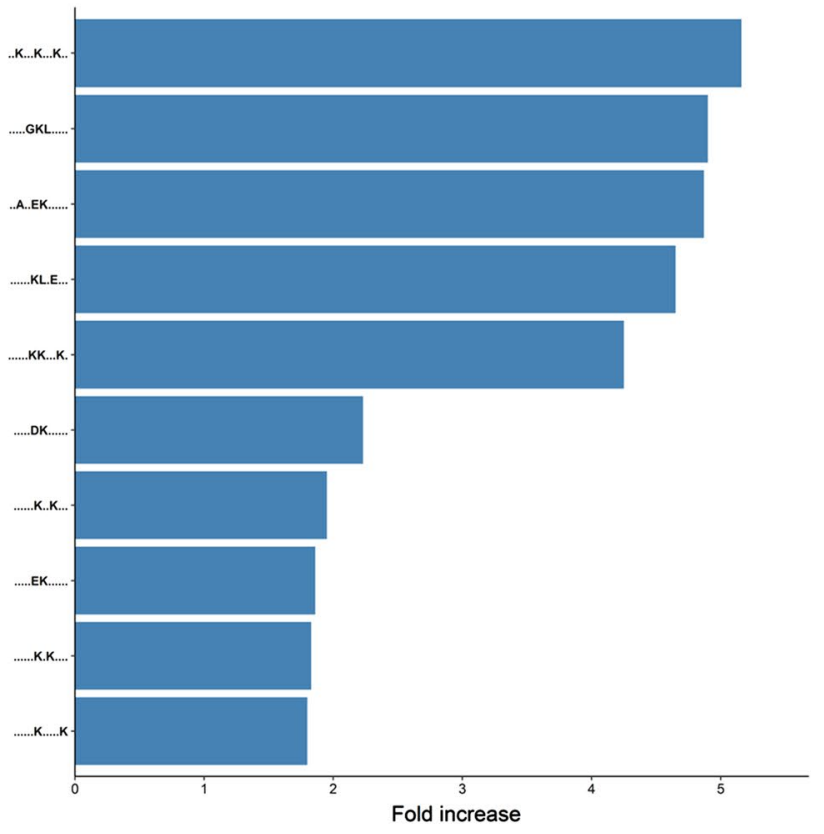

Fig. 1 a Motif-X analysis of over-represented motifs around the acetyl sites of the identified cervical acetyl proteins. $\mathbf{b}$ The number of acetyl peptides identified in each over-represented motif. $\mathbf{c}$ The fold increase of the enriched motifs compared with the background matches

(Abcam), anti-RUNX1 (Proteintech, Chicago, IL, USA), and anti-S100A9 (Proteintech) antibodies. After overnight incubation, the protein-A Sepharose beads were added, pelleted by centrifugation, and boiled for $5 \mathrm{~min}$. The proteins were subjected to immunoblotting with anti-acetylated-Lys antibody (Abcam). The protein bound was separated by SDS-PAGE and transferred onto PVDF membranes. The membranes were incubated with the secondary antibody and the bands were visualized using chemiluminescence. 
Table 1 List of differentially expressed acetylation sites from 3 paired samples

\begin{tabular}{|c|c|c|}
\hline Protein names & Protein accession & Peptides \\
\hline Protein S100-A9 & P06702 & $\begin{array}{l}\text { NEK(ac)VIEHIMEDLDTNADK } \\
\text { TCK(ac)MSQLER }\end{array}$ \\
\hline Acyl-CoA-binding protein & P07108 & AK(ac)WDAWNELK \\
\hline Protein SON & P18583 & RLTDLDK(ac)AQLLEIAK \\
\hline Nucleoprotein TPR & P12270 & NQK(ac)LTATTQK(ac)QEQIINTMTQDLR \\
\hline Mastermind-like protein 1 & Q92585 & ALAGVVLPSQGPGGASELSSAHQLQQIAAK(ac)QK \\
\hline Malate dehydrogenase & Q0QF37 & VSSFEEK(ac)MISDAIPELK \\
\hline 395 ribosomal protein $L 47$, mitochondrial & Q9HD33 & WDSMDALDK(ac)VVQER \\
\hline Histone H1.3 & P16402 & SETAPLAPTIPAPAEK(ac)TPVK \\
\hline CREB-binding protein & Q92793 & $\begin{array}{l}\text { FVYTCNECK(ac)HHVETR } \\
\text { NNK(ac)K(ac)TNK(ac)NK(ac)SSISR }\end{array}$ \\
\hline Histone acetyltransferase p300 & Q09472 & NAK(ac)KKNNKK \\
\hline CDNA FLJ55438, highly similar to Splicing factor 3 subunit 1 & B4E091 & TDIFGVEETAIGK(ac)K \\
\hline Histone cluster 1, H2bd & A8K9J7 & $\begin{array}{l}\text { SAPAPK(ac)KGSKKAVTK } \\
\text { LLLPGEELK(ac)HAVSEGTK }\end{array}$ \\
\hline Histone H2B type 1-B & P33778 & SAPAPK(ac)KGSKKAITK \\
\hline Histone cluster 2, H2bf & B4DR52 & SAPAPK(ac)KGSKKAVTK \\
\hline Histone H2B type 1-L & Q99880 & SAPAPK(ac)KGSKKAVTK \\
\hline Dihydropyrimidine dehydrogenase [NADP(+)] & Q12882 & EEK(ac)CEFLPFLSPR \\
\hline $\begin{array}{l}\text { 3-hydroxymethyl-3-methylglutaryl-Coenzyme A lyase (Hydroxymethylglutaricaci- } \\
\text { duria), isoform CRA_b }\end{array}$ & B1AK13 & DGLQNEK(ac)NIVSTPVK \\
\hline cDNA FLJ58863, highly similar to Protein NipSnap3A & B4DW81 & SYYLKPSK(ac)MNEFLENFEK \\
\hline Annexin & Q5TZZ9 & AAYLQETGKPLDETLK(ac)K \\
\hline cDNA FLJ54081, highly similar to Keratin, type II cytoskeletal 5 & B4E1T1 & $\begin{array}{l}\text { NK(ac)LAELEEALQK } \\
\text { LAELEEALQK(ac)AK } \\
\text { GELALK(ac)DAR }\end{array}$ \\
\hline $\begin{array}{l}\text { cDNA FLJ75211, highly similar to Homo sapiens ubiquitin specific peptidase like } \\
\text { 1, mRNA }\end{array}$ & A8K1B1 & GK(ac)LK(ac)ALK \\
\hline PRO1975 & Q9UHS8 & NCIHTDDDEK(ac)ISYR \\
\hline ATP synthase subunit beta & V9HW31 & VLDSGAPIK(ac)IPVGPETLGR \\
\hline ATP synthase subunit $\mathrm{O}$, mitochondrial & P48047 & QNK(ac)LEQVEK \\
\hline NAD kinase & J3KSP9 & MRDASLLQPFK(ac)ELCTHLMEK(ac)SRR \\
\hline NUMA1 protein & Q3SYK8 & CLEEK(ac)NEILQGK \\
\hline $\begin{array}{l}\text { Heterogeneous nuclear ribonucleoprotein U (Scaffold attachment factor A), } \\
\text { isoform CRA_a }\end{array}$ & Q7Z4Q5 & APQCLGK(ac)FIEIAAR \\
\hline Fatty acid synthase & AOAOU1RQF0 & DIMLATGK(ac)LSPDAIPGK \\
\hline Chloride intracellular channel protein & Q5SRT3 & NSNPALNDNLEK(ac)GLLK \\
\hline Prelamin-A/C & P02545 & ASSHSSQTQGGGSVTK(ac)K \\
\hline
\end{tabular}

1. Acetylated lysine is marked with "ac"

2. Lysine acetylation of P02545 is downregulated, others are upregulated in tumor tissues compared with adjacent normal tissues

\section{Results}

\section{Global profiling of protein lysine acetylation cervical carcinogenesis}

To investigate the regulatory role of protein lysine acetylation in cervical carcinogenesis, we performed a quantitative, MS-based acetylproteomic analysis of primary cancer tissues and corresponding adjacent normal tissues from three patients with cervical squamous cell carcinoma. After removing the redundancies, we identified a total of 928 lysine acetylation sites from 1547 proteins, in which 495 lysine acetylation sites corresponding to 296 proteins were quantified (Additional files 1, 2: Tables S1, S2).

\section{Conserved motifs flanking the acetyl sites}

To further identify the acetylation conserved motifs in cervical tissues, the amino acid sequence flanking the acetyl sites were used for Motif-X analysis. Figure 1a 
Table 2 List of specifically expressed acetylation sites in tumor samples

\begin{tabular}{|c|c|c|}
\hline Protein names & Protein accession & Peptides \\
\hline Serine arginine-rich pre-mRNA splicing factor SR-A1, isoform CRA_a & A0A024QZH6 & TK(ac)VK(ac)AK(ac)AGAK(ac)K \\
\hline Scavenger receptor class B member 1 & F5H5E8 & GCSAK(ac)AR \\
\hline cDNA FLJ58633, highly similar to Leucine-rich repeat-containing protein 27 & B4DW88 & PSKEK(ac)SPQASK \\
\hline Perilipin-3 & K7ER39 & TVCDAAEK(ac)GVR \\
\hline ATP synthase $F(0)$ complex subunit B1, mitochondrial & Q5QNZ2 & EQEHMINWVEK(ac)HVVQSISTQQEK \\
\hline $\begin{array}{l}\text { CDNA FLJ75700, highly similar to Homo sapiens complement component 1, q } \\
\text { subcomponent binding protein (C1QBP), nuclear gene encoding mitochon- } \\
\text { drial protein, mRNA }\end{array}$ & A8K651 & AFVDFLSDEIK(ac)EER \\
\hline Runt-related transcription factor 1 & C9JWM1 & $\begin{array}{l}\text { FTPPSTALSPGK(1)MSEALPLGAPDAGAALAGK(ac)LR } \\
\text { MSEALPLGAPDAGAALAGK(ac)LR }\end{array}$ \\
\hline Fibronectin type III domain-containing protein 1 & J3KNQ2 & ILANGGAPRK(ac)PQLR \\
\hline Protein S100-A9 & P06702 & ENK(ac)NEKVIEHIMEDLDTNADK \\
\hline Non-histone chromosomal protein HMG-14 & A6NL93 & TEESPASDEAGEK(ac)EAK \\
\hline Small ubiquitin-related modifier 1 & B8ZZJ0 & SDQEAKPSTEDLGDK(ac)K \\
\hline $\begin{array}{l}\text { cDNA FLJ45654 fis, clone CTONG2012123, moderately similar to Mus muscu- } \\
\text { lus enabled homolog (Drosophila) (Enah) }\end{array}$ & Q6ZSB8 & IAEK(ac)GSTIETEQK \\
\hline RNA polymerase II subunit A C-terminal domain phosphatase & A0A0J9YWJ4 & IYDSNTGK(ac)LIR \\
\hline $\begin{array}{l}\text { cDNA FLJ45012 fis, clone BRAWH3013264, highly similar to Homo sapiens } \\
\text { SNF2 histone linker PHD RING helicase (SHPRH), mRNA }\end{array}$ & B3KX98 & EAVK(ac)NLEGPPSR \\
\hline Epididymis secretory sperm binding protein & AOAOS2Z4C3 & AIEMLGGELGSK(ac)IPVHPNDHVNK \\
\hline Centrosomal protein of $70 \mathrm{kDa}$ & C9J0F4 & FPVAPK(ac)PQDSSQPSDR \\
\hline 3-hydroxyisobutyryl-CoA hydrolase, mitochondrial & A0A140VJL0 & AVLIDK(ac)DQSPK \\
\hline Proteasome subunit alpha type & Q6IB71 & LVLSK(ac)LYEEGSNKR \\
\hline Golgin subfamily A member $8 \mathrm{H}$ & PoCJ92 & EAMSSFMDHLEEKADLSELVK(ac)K(ac)K \\
\hline Signal transducing adapter molecule 1 & A6NMU3 & TEK $(\mathrm{ac}) \mathrm{K}(\mathrm{ac}) \mathrm{TVQF}$ \\
\hline Protein HIRA & B4DSW6 & ATYIGPSTVFGSSGK(ac)LANVEQWR \\
\hline $\begin{array}{l}\text { cDNA FLJ77442, highly similar to Homo sapiens grainyhead-like } 2 \text { (Dros- } \\
\text { ophila), mRNA }\end{array}$ & A8K9Y8 & GQASQTQCNSSSDGK(ac)LAAIPLQK \\
\hline Histone H3 & B4E380 & K(ac)SAPSTGGVK(ac)KPHR \\
\hline $\begin{array}{l}\text { CDNA FLJ50838, highly similar to Apoptotic chromatin condensation inducer } \\
\text { in thenucleus }\end{array}$ & B4DQZ7 & QQQEK(ac)EMK \\
\hline cDNA FLJ53691, highly similar to Serotransferrin & B4E1B2 & YLGEEYVK(ac)AVGNLR \\
\hline Treacle protein (Fragment) & J3KQ96 & SLGNILQAKPTSSPAK(ac)GPPQK \\
\hline Protein NipSnap homolog 3B & F2Z3L7 & IDK(ac)QETEITYLIPWSK \\
\hline Tetratricopeptide repeat protein 22 & H0Y486 & QVLK(ac)SEDPR \\
\hline Nuclear pore complex protein Nup93 & H3BVE2 & SDTK(ac)PIINK \\
\hline Protein S100-A8 & P05109 & ALNSIIDVYHK(ac)YSLIK \\
\hline Cytochrome P450 1A2 & Q6NWU3 & PLSEK(ac)MMLFGMGK \\
\hline Serpin B3 & P29508 & INSWVESQTNEK(ac)IK \\
\hline Cell growth-inhibiting protein 34 & Q08ES8 & AEEILEK(ac)GLK \\
\hline Elongation factor 1-alpha & Q6IPT9 & DGNASGTTLLEALDCILPPTRPTDK(ac)PLR \\
\hline Histone acetyltransferase p300 & Q09472 & $\begin{array}{l}\text { VVQHTK(ac)GCK(ac)R } \\
\text { EESTAASETTEGSQGDSK(ac)NAKKK }\end{array}$ \\
\hline PEST proteolytic signal-containing nuclear protein & Q8WW12 & SAEEEAADLPTK(ac)PTK \\
\hline CREB-binding protein & Q92793 & EESTAASETTEGSQGDSK(ac)NAKKK \\
\hline Protein S100-A16 & Q96FQ6 & $\begin{array}{l}\text { AADK(ac)LIQNLDANHDGR } \\
\text { K(ac)AADKLIQNLDANHDGR }\end{array}$ \\
\hline MRG/MORF4L-binding protein & Q9NV56 & VTDK(ac)VLTANSNPSSPSAAK \\
\hline Histone-lysine N-methyltransferase 2B & Q9UMN6 & SPPAPPPYK(ac)APR \\
\hline
\end{tabular}

Acetylated lysine is marked with "ac" 
Table 3 List of specifically expressed acetylation sites in adjacent samples

\begin{tabular}{|c|c|c|}
\hline Protein names & Protein accession & Peptides \\
\hline Myosin, heavy polypeptide 11, smooth muscle, isoform CRA_b & A0A024QZJ6 & $\begin{array}{l}\text { K(ac)K(ac)LQDFASTVEALEEGK } \\
\text { KLQAQMK(ac)DFQR } \\
\text { SFVEK(ac)LCTEQGSHPK }\end{array}$ \\
\hline Apolipoprotein A-I, isoform CRA_a & A0A024R3E3 & LEALK(ac)ENGGAR \\
\hline Beta I spectrin form betal sigma3 & Q8WX82 & $\begin{array}{l}\text { NIK(ac)QLASR } \\
\text { TQLVDTADK(ac)FR }\end{array}$ \\
\hline Ribosomal protein & A0A024RCW3 & DIEALKKLNKNK(ac)K \\
\hline Testicular tissue protein Li 70 & A0A140VJJ6 & $\begin{array}{l}\text { TSEVK(ac)QLIK } \\
\text { TSTADYAMFK(ac)VGPEADKYR }\end{array}$ \\
\hline Interleukin-33 & A0A119R150 & ISTAK(ac)WK \\
\hline Desmin, isoform CRA_a & Q53SB5 & FANYIEK(ac)VR \\
\hline ZNF483 protein & Q6P088 & $\mathrm{K}(\mathrm{ac}) \mathrm{LEPFQK}$ \\
\hline $\begin{array}{l}\text { cDNA FLJ77679, highly similar to Homo sapiens potassium voltage-gated channel, } \\
\text { shaker-related subfamily, beta member } 2 \text { (KCNAB2), transcript variant 1, mRNA }\end{array}$ & A8K1X9 & AEVLGNNIK(ac)K(ac)K(ac)GWR \\
\hline $\begin{array}{l}\text { cDNA, FLJ95005, highly similar to Homo sapiens kinesin family member } 11 \text { (KIF11), } \\
\text { mRNA }\end{array}$ & B2RAM6 & MASQPNSSAKKKEEK(ac)GK \\
\hline Actin, alpha 2, smooth muscle, aorta & D2JYH4 & EITALAPSTMK(ac)IK \\
\hline Histone H2B & 16L9F7 & PEPVK(ac)SAPVPK \\
\hline Alternative protein GATAD2A & L8ECH2 & MMELK(ac)VNR \\
\hline Fibrinogen alpha chain & P02671 & SRIEVLK(ac)R \\
\hline Fructose-bisphosphate aldolase & V9HWN7 & ALSDHHIYLEGTLLK(ac)PNMVTPGHACTQK \\
\hline Galectin-10 & Q05315 & DISLTK(ac)FNVSYLK \\
\hline Uncharacterized protein DKFZp686H1812 & Q5HYE3 & VLEQGLEK(ac)CTQATR \\
\hline cDNA FLJ26541 fis, clone KDN09394 & Q6ZP39 & MQIK(ac)TTLRYHLTPVK(ac)MALIQK \\
\hline
\end{tabular}

Acetylated lysine is marked with "ac"

shows the top 10 over-represented motifs, among which kxxxkxxxk, GkL, AxxEk, kLxE, and kkxxxk are the most enriched motifs with over four-fold increases when compared with the background matches (Fig. 1b, c), suggesting that the residues including $\mathrm{G}, \mathrm{k}$, and $\mathrm{L}$ are favored by protein lysine acetylation. These motif models and residue preferences offer useful information for the acetyl site prediction of the unknown acetyl proteins.

\section{Differentially acetylated peptides between primary cervical cancer tissues and their corresponding adjacent normal tissues}

Furthermore, we found 41 differentially expressed lysine acetylation sites corresponding to 30 proteins in cervical cancer tissues compared with adjacent normal tissues (Fold change $>2$ and $\mathrm{P}<0.05$ ), of which 1 was downregulated, 40 were upregulated (Table 1). Moreover, 49 lysine acetylation sites corresponding to 40 proteins were specifically expressed in cancer tissues (Table 2); 26 lysine acetylation sites corresponding to 18 proteins were specifically expressed in normal adjacent tissues (Table 3). The gene ontology analysis showed proteins identified from differentially and specifically acetylated peptides were associated "metabolic process", "cellular process" and "response to stimulus" under the category of "biological process" (Fig. 2a). In support of the "metabolic process" annotation, the "molecular function" of the proteins was mostly categorized to "catalytic activity" and "binding" (Fig. 2b). In terms of "cellular component", the majority of the proteins are located in the cell and organelle (Fig. 2c). Moreover, bacterium response under the category of "biological process", acid-binding under the category of "molecular function", and nucleus under the category of "cellular component" were significantly enriched (Fig. 2d). On the basis of acetylation intensity in cervical tissues, a hierarchical clustering analysis was conducted to visualize the acetylation dynamics, revealing that cervical cancer tissues are distinctly different from their normal corresponding tissues (Fig. 3). The protein name can be got from Table 1 with the accession names.

\section{Kyoto encyclopedia of genes and genomes (KEGG) pathway enrichment analysis and protein-protein interaction (PPI) analysis of the proteins corresponding to differentially acetylated peptides}

Moreover, KEGG analysis was carried out to assess the potential roles of proteins from differentially and specifically acetylated peptides in cervical carcinogenesis. The result showed that ten pathways, such as Notch signaling 

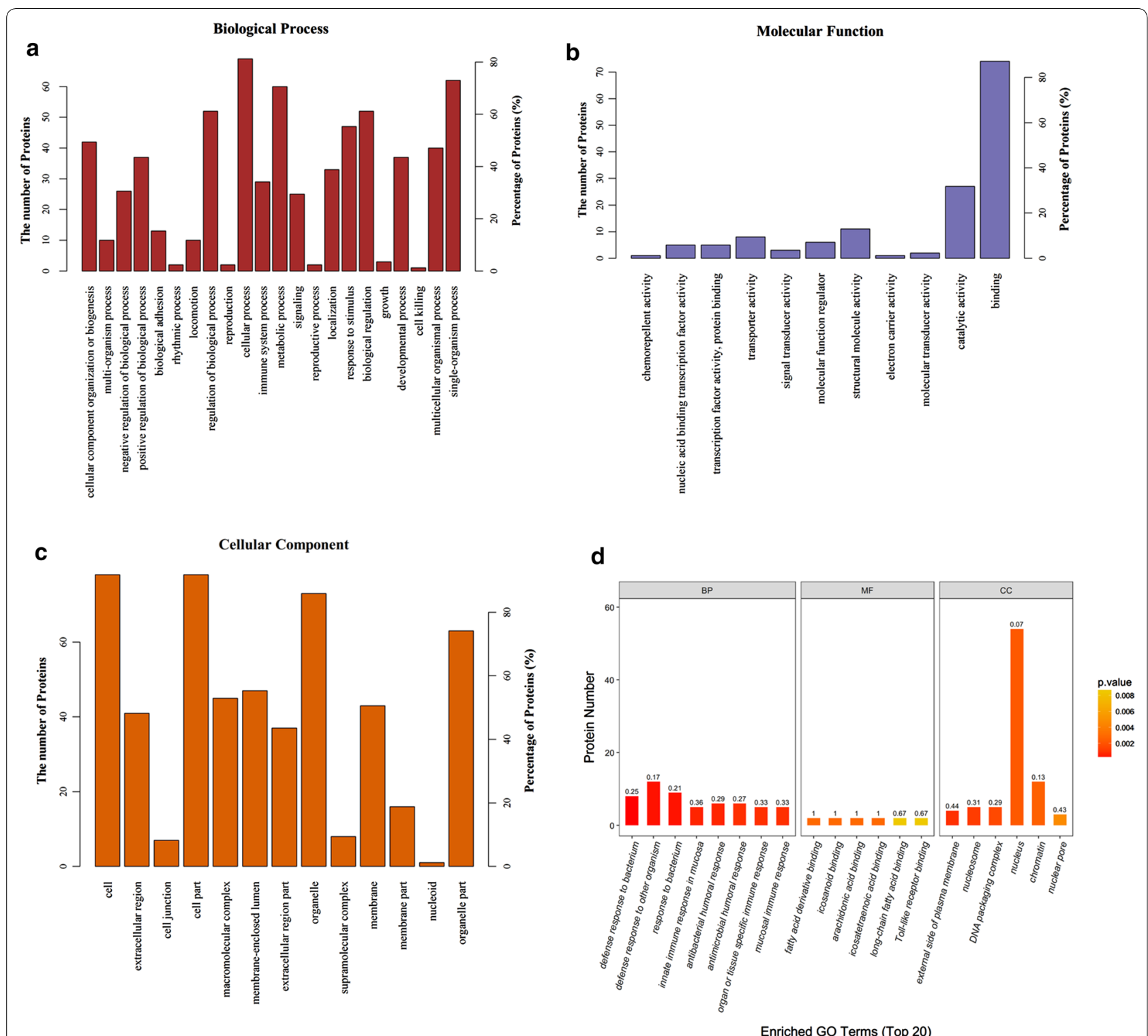

Fig. $2 \mathrm{GO}$ analysis of proteins from differentially and specifically acetylated peptides in terms of biological process $\mathbf{a}$; molecular function $\mathbf{b}$; cellular competent c. d The top 20 enriched GO terms of proteins

pathway, viral carcinogenesis, RNA transport, and JakSTAT signaling pathway were predominantly over-represented (Fig. $4 \mathrm{a} ; \mathrm{P}<0.05$ ). The number of proteins fallen into the KEGG pathways is shown in Fig. 4b. To investigate how these proteins are functionally associated with each other, PPI analysis was conducted by using the String 10.0 and visualized by Cytoscape. The results showed that 52 nodes (proteins) and 98 edges (interaction-ship) were observed, indicating a highly profound network of the acetyl-proteins in cervical carcinogenesis (Fig. 5; Additional file 3: Table S3). Additionally, several differentially acetylated proteins were validated by IP and Western blot analysis. As illustrated in Fig. 6, consistent with the acetylome results, CREBBP and S100A9 were up-acetylated in cervical cancer tissues compared with adjacent normal tissues. However, the acetylated levels of MYH11 and RUNX1 were not significantly altered.

\section{Discussion}

Recently, increasing evidence indicates that post-translational modifications, including lysine acetylation, play essential regulatory roles in multiple biological processes. 


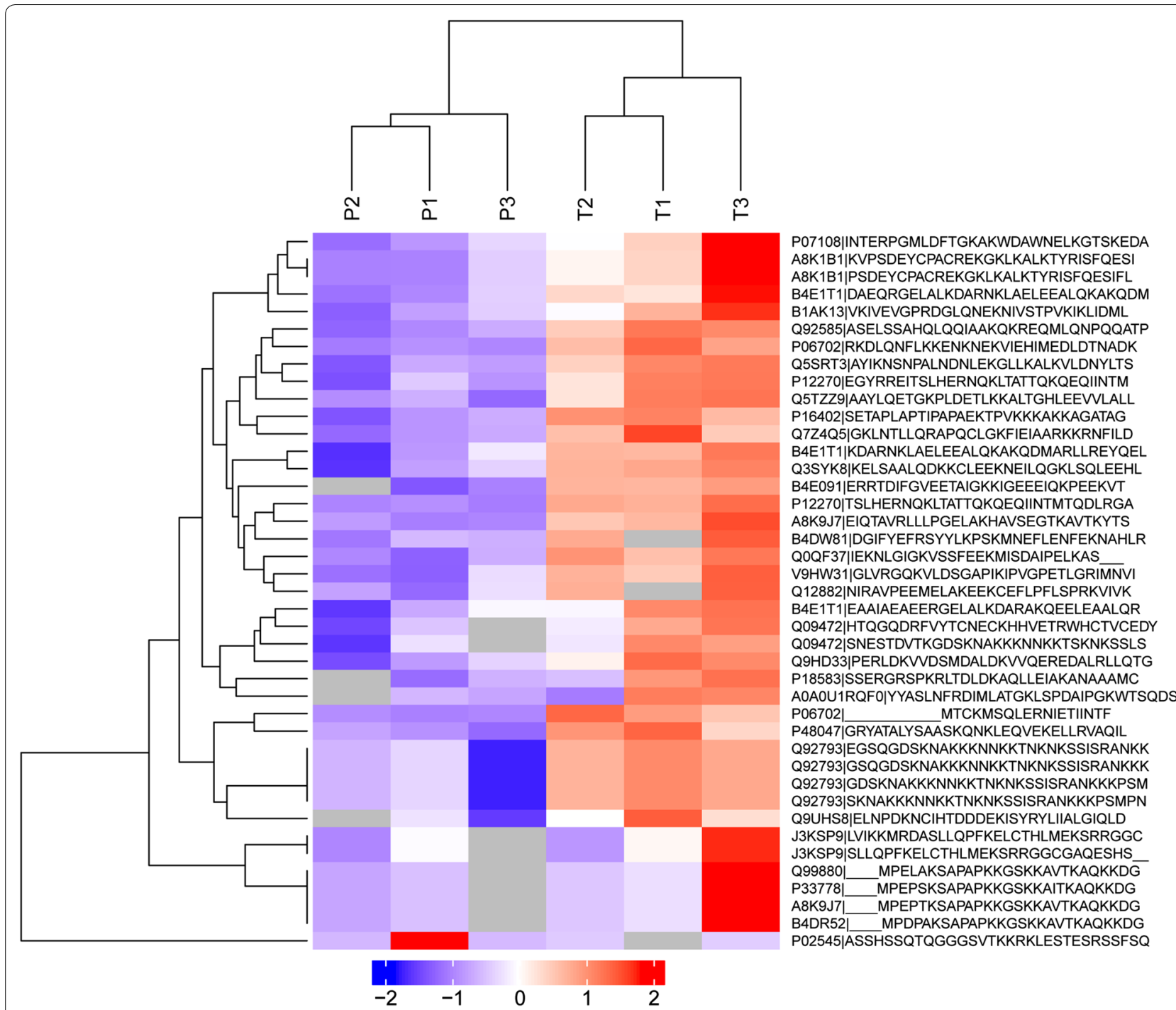

Fig. 3 Acetylation quantification heatmap of proteins from differentially acetylated peptides in cervical cancer tissues and corresponding adjacent normal tissues

Several acetylome analyses have been performed to understand the function of acetylation proteins in different human cancers [16-18]. To the best of our knowledge, there are no reports on large scale analyses of aberrant lysine acetylation in cervical cancer development. Herein, we report the first quantitative profiling of lysine acetylation in cervical tissues. As a result, we identified a total of 928 lysine acetylation sites from 1547 protein, in which 495 lysine acetylation sites were quantified. Further, 41 lysine acetylation sites were differentially expressed in cervical cancer tissues compared with adjacent normal tissues, 75 lysine acetylation sites were specifically expressed in cancer tissues or normal tissues.
Acetylation is the most common post-translational modifications of histones and is regulated by histone acetylation and deacetylation [19]. Previous studies have shown that overexpression of histone deacetylases (HDACs) is associated with tumorigenesis, and the inhibition of HDACs prevents proliferation and leads to apoptosis in many cancer cells $[20,21]$. HDACs are believed to be potential novel therapeutic targets for human cancer [22]. In the current study, we consistently found several histones are up-acetylated in cervical cancer tissues compared with adjacent normal tissues, including histone $2 \mathrm{~B}$ and histone 3 . Our results further support the notion that histone acetylation plays crucial roles in cervical carcinogenesis. 

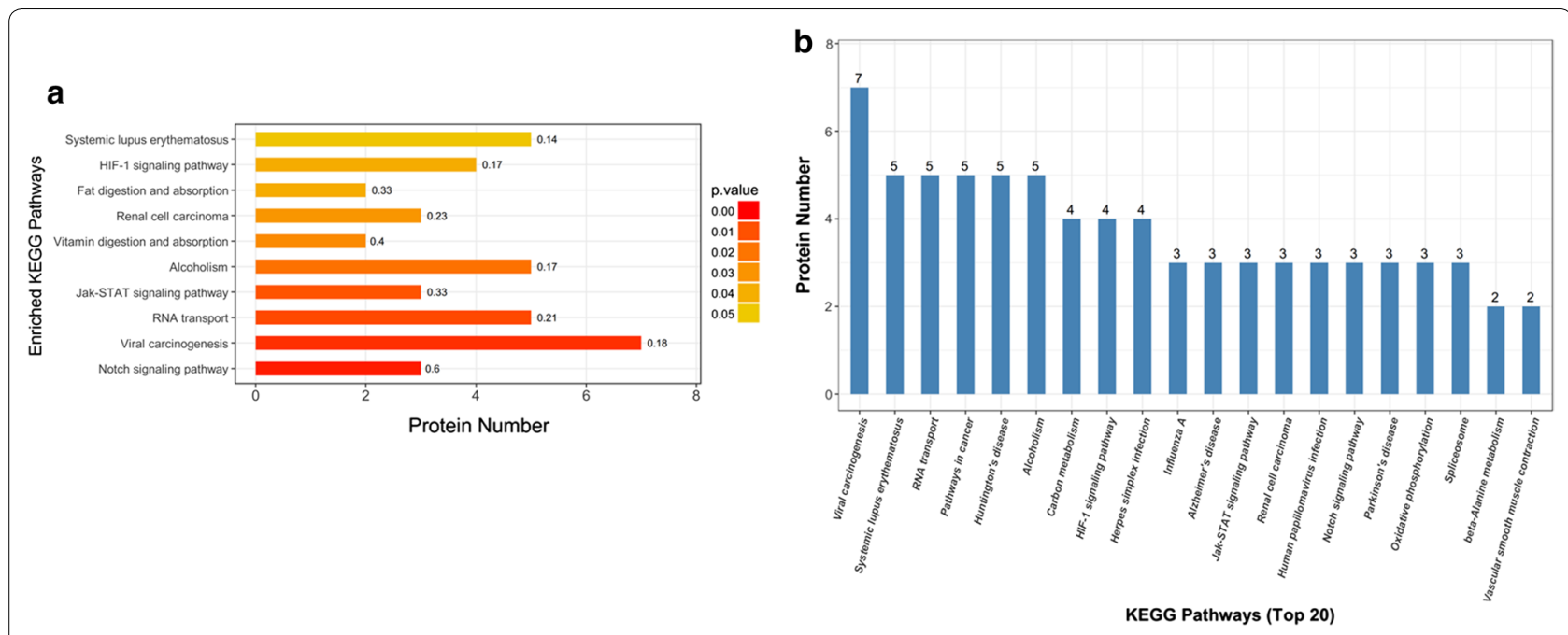

Fig. 4 The enriched KEGG pathways of proteins from differentially and specifically acetylated peptides in the sequence of P-value $\mathbf{a}$ and protein numbers $\mathbf{b}$

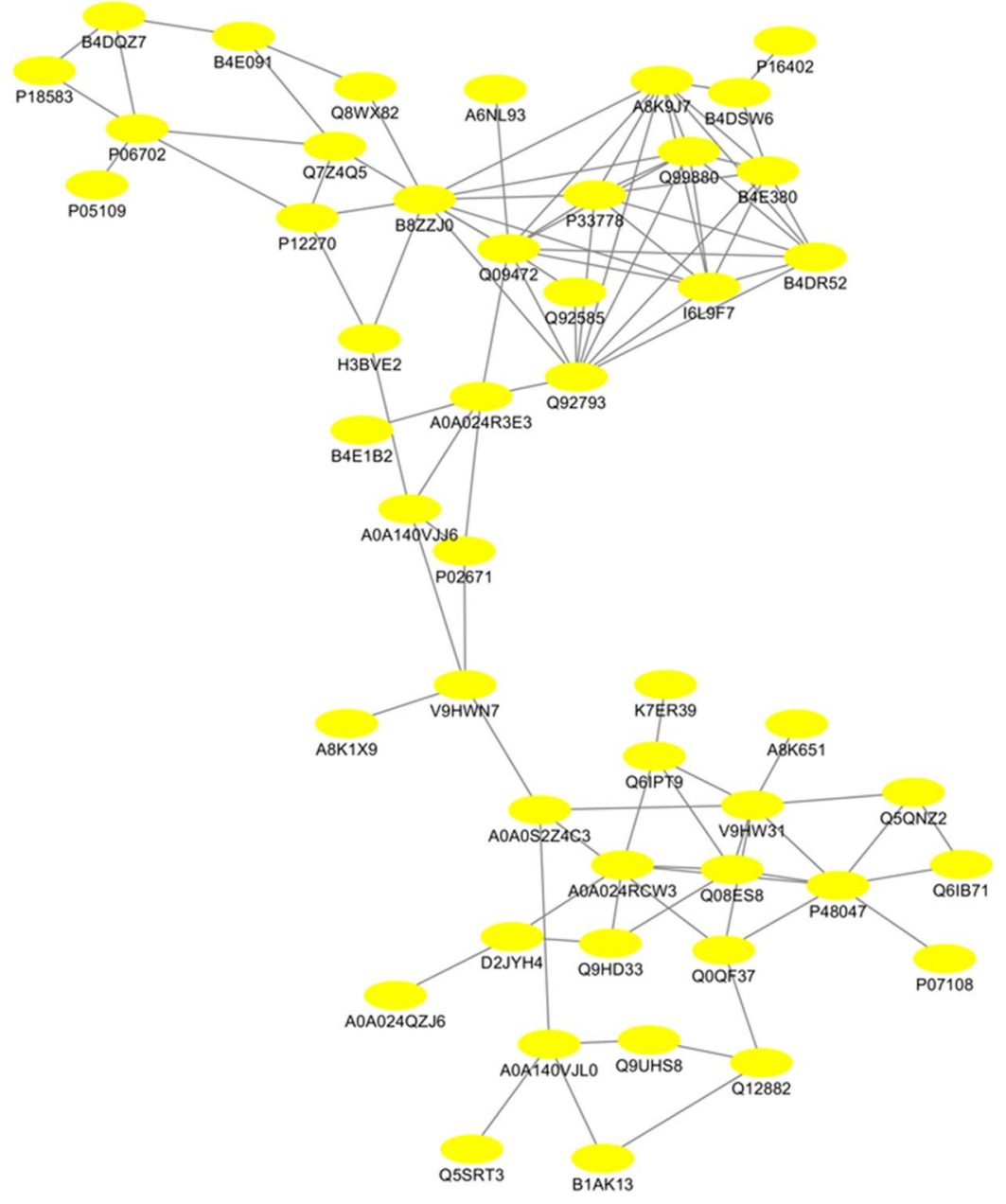

Fig. 5 Protein-protein interaction (PPI) networks of proteins from differentially and specifically acetylated peptides identified in the cervical tissues 


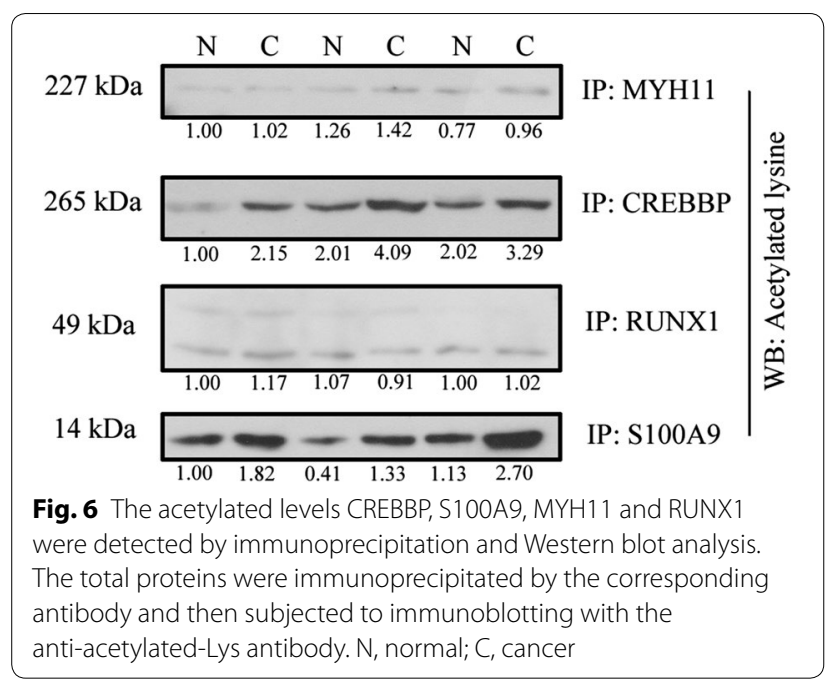

CREB-binding protein (CREBBP), a transcriptional co-activator, functions as histone acetyltransferases and involved in various biological processes, including embryonic development, homeostasis and cell growth [23-25]. CREBBP has also been shown to mediate the acetylation of both histone and non-histone proteins and thereby contribute to gene transactivation or repression [26-28]. Because of the sequence similarity with protein p300, CREBBP interacts with p300 and transcriptionally co-activates a variety of different transcriptional factors [29-31]. Furthermore, the inhibition of histone acetyltransferase activity of CREBBP and/or p300 has been reported to inhibit cancer cell growth in vitro and in vivo in many human cancers [32-34]. In support to the previous findings, the present study found that both CREBBP and p300 were up-acetylated in cervical cancer tissues compared with adjacent normal tissues, suggesting a potential role of CREBBP/p300 in cervical carcinogenesis. However, further studies are required to elucidate mechanisms by which CREBBP/p300 contributes to cervical carcinogenesis.

HPV is the leading risk factor for cervical cancer, and HPV infection has been shown to cause aberrant acetylation. For instance, Jansma and colleagues have documented that the oncoprotein E7 from human HPV strains mediates the interactions between $\mathrm{CBP} / \mathrm{p} 300$ and $\mathrm{pRb}$ and promotes $\mathrm{pRb}$ acetylation, leading to disruption of cell cycle control [29]. In this study, the three patients were HPV infected, and we found that viral carcinogenesis was predominantly over-represented in KEGG analysis. More importantly, our acetylome analysis and IP experiments demonstrated that CREBBP and p300 were up-acetylated in cervical cancer tissues compared with adjacent normal tissues. It seems reasonable to propose that HPV infection changes acetylation levels of many proteins in cervical cancer and contributes to cervical carcinogenesis.

\section{Conclusions}

our data not only enhance our understanding of acetylproteome dataset in cervical cancer tissues but also provide novel insights into the role of protein lysine acetylation in cervical carcinogenesis.

\section{Supplementary information}

Supplementary information accompanies this paper at https://doi. org/10.1186/s12935-020-01266-z.

Additional file 1: Table S1. A total of 928 lysine acetylation sites were identified by label-free quantitative proteomics.

Additional file 2: Table S2. A total of 1547 proteins were identified by label-free quantitative proteomics

Additional file 3: Table S3. Protein-protein interaction (PPI) networks of proteins identified from differential peptides in the cervical tissues.

\section{Acknowledgements}

Not applicable.

\section{Authors' contributions}

$Y W$ and $Y Z$ designed the experiment. $L Z, W W$, and SZ performed the experiments. $L Z, W W, S Z, Y W, W G$, and $Y L$ analyzed the data. $L Z$ and $Y W$ wrote the manuscript. All authors read and approved the final manuscript.

\section{Funding}

This study was supported by grants from the Natural Science Foundation of Heilongjiang Province (No. H2017045), the National Natural Science Foundation of China (No. 81672584), the Key Project for Petrel Foundation of Harbin Medical University Cancer Hospital (No. JJZD2020-07), and Harbin Medical University Graduate Research and Practice Innovation Project (No. YJSSJCX2019-51HYD).

\section{Availability of data and materials}

The datasets supporting the conclusions of the current study are available from the corresponding author on reasonable request. Please contact corresponding author, if you want to request the dataset.

\section{Ethics approval and consent to participate}

This study was approved by the Ethics Review Board of Harbin Medical University Cancer Hospital and adhered to the principles of the Declaration of Helsinki and Title 45, U.S. Code of Federal Regulations, Part 46, Protection of Human Subjects, effective December 13, 2001.

\section{Consent for publication}

All authors approved publication of the manuscript.

\section{Competing interests}

The authors declare that they have no competing interests.

\section{Author details}

${ }^{1}$ Department of Gynecology, Harbin Medical University Cancer Hospital, No. 150 Haping Road, Nangang District, Harbin 150081, Heilongjiang Province, China. ${ }^{2}$ School of Basic Medical Sciences, Qiqihar Medical University, Qiqihar 161006, Heilongjiang, China. ${ }^{3}$ Medical Research Center, Yue Bei People's Hospital Affiliated to Shantou University Medical College, Shaoguan 512025, Guangdong, China.

Received: 18 January 2020 Accepted: 14 May 2020

Published online: 24 May 2020 


\section{References}

1. Torre LA, Siegel RL, Ward EM, Jemal A. Global cancer incidence and mortality rates and trends-an update. Cancer Epidemiol Biomarkers Prev. 2016;25(1):16-27.

2. Fidler MM, Gupta S, Soerjomataram I, Ferlay J, Steliarova-Foucher E, Bray F. Cancer incidence and mortality among young adults aged 20-39 years worldwide in 2012: a population-based study. Lancet Oncol. 2017;18(12):1579-89.

3. Goodman A. HPV testing as a screen for cervical cancer. BMJ. 2015;350:h2372.

4. Lapresa M, Parma G, Portuesi R, Colombo N. Neoadjuvant chemotherapy in cervical cancer: an update. Expert Rev Anticancer Ther. 2015;15(10):1171-81.

5. Brucker SY, Ulrich UA. Surgical treatment of early-stage cervical cancer. Oncol Res Treat. 2016;39(9):508-14.

6. Mallmann P, Mallmann C. Neoadjuvant and adjuvant chemotherapy of cervical cancer. Oncol Res Treat. 2016;39(9):522-4.

7. Aasen T, Johnstone S, Vidal-Brime L, Lynn KS, Koval M. Connexins: synthesis, post-translational modifications, and trafficking in health and disease. Int J Mol Sci. 2018;19(5):1296.

8. Kori Y, Sidoli S, Yuan ZF, Lund PJ, Zhao X, Garcia BA. Proteome-wide acetylation dynamics in human cells. Sci Rep. 2017;7(1):10296.

9. Hubbert C, Guardiola A, Shao R, Kawaguchi Y, Ito A, Nixon A, et al. HDAC6 is a microtubule-associated deacetylase. Nature. 2002;417(6887):455-8.

10. Onyango P, Celic I, McCaffery JM, Boeke JD, Feinberg AP. SIRT3, a human SIR2 homologue, is an NAD-dependent deacetylase localized to mitochondria. Proc Natl Acad Sci USA. 2002;99(21):13653-8.

11. Kim SC, Sprung R, Chen Y, Xu Y, Ball H, Pei J, et al. Substrate and functional diversity of lysine acetylation revealed by a proteomics survey. Mol Cell. 2006;23(4):607-18.

12. Choudhary C, Kumar C, Gnad F, Nielsen ML, Rehman M, Walther TC, et al. Lysine acetylation targets protein complexes and co-regulates major cellular functions. Science. 2009:325(5942):834-40.

13. Kaypee S, Sudarshan D, Shanmugam MK, Mukherjee D, Sethi G, Kundu TK. Aberrant lysine acetylation in tumorigenesis: implications in the development of therapeutics. Pharmacol Ther. 2016:162:98-119.

14. Gil J, Ramirez-Torres A, Encarnacion-Guevara S. Lysine acetylation and cancer: a proteomics perspective. J Proteomics. 2017:150:297-309.

15. Tafrova Jl, Tafrov ST. Human histone acetyltransferase 1 (Hat1) acetylates lysine 5 of histone H2A in vivo. Mol Cell Biochem. 2014;392(1-2):259-72.

16. Zhu D, Hou L, Hu B, Zhao H, Sun J, Wang J, et al. Crosstalk among proteome, acetylome and succinylome in colon cancer HCT116 cell treated with sodium dichloroacetate. Sci Rep. 2016;6:37478.

17. Tatham MH, Cole C, Scullion P, Wilkie R, Westwood NJ, Stark LA, et al. A proteomic approach to analyze the aspirin-mediated lysine acetylome. Mol Cell Proteomics. 2017;16(2):310-26.

18. Gu X, Hua Z, Dong Y, Zhan Y, Zhang X, Tian W, et al. Proteome and acetylome analysis identifies novel pathways and targets regulated by perifosine in neuroblastoma. Sci Rep. 2017:7:42062.

19. Grunstein M. Histone acetylation in chromatin structure and transcription. Nature 1997:389(6649):349-52

20. Witt O, Deubzer HE, Milde T, Oehme I. HDAC family: what are the cancer relevant targets? Cancer Lett. 2009:277(1):8-21.
21. Weichert W. HDAC expression and clinical prognosis in human malignancies. Cancer Lett. 2009;280(2):168-76.

22. Zhang H, Shang YP, Chen HY, Li J. Histone deacetylases function as novel potential therapeutic targets for cancer. Hepatol Res. 2017;47(2):149-59.

23. Valor LM, Viosca J, Lopez-Atalaya JP, Barco A. Lysine acetyltransferases CBP and p300 as therapeutic targets in cognitive and neurodegenerative disorders. Curr Pharm Des. 2013:19(28):5051-64.

24. Stachowiak MK, Birkaya B, Aletta JM, Narla ST, Benson CA, Decker B, et al. Nuclear FGF receptor-1 and CREB binding protein: an integrative signaling module. J Cell Physiol. 2015;230(5):989-1002.

25. Liu Y, Wang L, Han R, Beier UH, Akimova T, Bhatti T, et al. Two histone/ protein acetyltransferases, CBP and p300, are indispensable for Foxp3 + T-regulatory cell development and function. Mol Cell Biol. 2014:34(21):3993-4007.

26. Cai K, Wan Y, Wang Z, Wang Y, Zhao X, Bao X. C5a promotes the proliferation of human nasopharyngeal carcinoma cells through PCAF-mediated STAT3 acetylation. Oncol Rep. 2014;32(5):2260-6.

27. Cazzalini O, Sommatis S, Tillhon M, Dutto I, Bachi A, Rapp A, et al. CBP and p300 acetylate PCNA to link its degradation with nucleotide excision repair synthesis. Nucleic Acids Res. 2014;42(13):8433-48.

28. Dancy BM, Cole PA. Protein lysine acetylation by p300/CBP. Chem Rev. 2015;115(6):2419-52.

29. Jansma AL, Martinez-Yamout MA, Liao R, Sun P, Dyson HJ, Wright PE. The high-risk HPV16 E7 oncoprotein mediates interaction between the transcriptional coactivator CBP and the retinoblastoma protein $\mathrm{pRb}$. J Mol Biol. 2014;426(24):4030-48.

30. Jia Y, Nie F, Du A, Chen Z, Qin Y, Huang T, et al. Thymine DNA glycosylase promotes transactivation of beta-catenin/TCFs by cooperating with CBP. Mol Cell Biol. 2014;6(3):231-9.

31. Xiao Y, Wang J, Qin Y, Xuan Y, Jia Y, Hu W, et al. Ku80 cooperates with CBP to promote COX-2 expression and tumor growth. Oncotarget. 2015;6(10):8046-61.

32. Arensman MD, Telesca D, Lay AR, Kershaw KM, Wu N, Donahue TR, et al. The CREB-binding protein inhibitor ICG-001 suppresses pancreatic cancer growth. Mol Cancer Ther. 2014;13(10):2303-14.

33. Gajer JM, Furdas SD, Grunder A, Gothwal M, Heinicke U, Keller K, et al. Histone acetyltransferase inhibitors block neuroblastoma cell growth in vivo. Oncogenesis. 2015:4:e137.

34. Giotopoulos G, Chan WI, Horton SJ, Ruau D, Gallipoli P, Fowler A, et al. The epigenetic regulators CBP and p300 facilitate leukemogenesis and represent therapeutic targets in acute myeloid leukemia. Oncogene. 2016:35(3):279-89.

\section{Publisher's Note}

Springer Nature remains neutral with regard to jurisdictional claims in published maps and institutional affiliations.

Ready to submit your research? Choose BMC and benefit from

- fast, convenient online submission

- thorough peer review by experienced researchers in your field

- rapid publication on acceptance

- support for research data, including large and complex data types

- gold Open Access which fosters wider collaboration and increased citations

- maximum visibility for your research: over 100M website views per year

At BMC, research is always in progress.

Learn more biomedcentral.com/submissions 